\title{
Effects of Ground Surface Decontamination on the Air Radiation Dose Rate
}

\section{-Results of a Decontamination Trial at a Playground Lot in a Fukushima Residential Area-}

\author{
Akihiro TAGAWA ${ }^{1, *}$ \\ ${ }^{1}$ Headquarters of Fukushima Partnership Operations, Japan Atomic Energy Agency, 2-2-2 Uchisaiwai-cho, \\ Chiyoda-ku. Tokyo 100-8577, Japan
}

\begin{abstract}
The Japan Atomic Energy Agency decontaminated schools, playgrounds, swimming pools, and houses in nonevacuated, less-contaminated areas in Fukushima for environmental restoration. A small, $150 \mathrm{~m}^{2}$ playground lot in the residential area was chosen for decontamination demonstration, which used routinely available tools and commodities to carry out the work. The surfaces of playground lot equipment, such as swings, slides, and horizontal iron bars, were completely decontaminated by brushing with water and/or detergent. Side gutters around the playground lot were cleaned by removing the mud and then brushed and washed with a high-pressure water jet ( $7 \mathrm{MPa}$ ). The air dose rate at the playground lot was dominated by radiation from the ground surface and adjacent surroundings, such as apartments and rice fields. Two or three centimeters of the surface soil contaminated with cesium was removed manually with shovels, hoes, and other gardening tools. This significantly reduced the average air dose rate of the entire playground lot from $1.5 \mu \mathrm{Sv} / \mathrm{h}$ before decontamination to $0.6 \mu \mathrm{Sv} / \mathrm{h}$. These results showed that ground surface decontamination can contribute measurably to the reduction in air dose rate in relatively small areas in residential areas.
\end{abstract}

KEYWORDS: Fukushima, environmental restoration, playground lot, decontamination, side gutter, high-pressure water washing, air dose rate, ground surface, cesium, gardening tools

\section{Foreword}

As a result of the nuclear accident resulting from the Great East Japan Earthquake on March 112011 , it is necessary to decontaminate radioactive materials dispersed into the environment. The Japan Atomic Energy Agency is engaged in the decontamination and environmental restoration of schools, playgrounds, swimming pools, and houses in the areas in Fukushima where the order to evacuate was not issued. In the future, the general public is expected to participate in the decontamination work without prior training in environments other than the evacuation-directive areas. Therefore, it is important to show that the spaces in which children

\footnotetext{
${ }^{*}$ Corresponding author, E-mail: tagawa.akihiro@jaea.go.jp

DOI : 10.15669 /fukushimainsights. Vol.4.78

(C) 2021 Atomic Energy Society of Japan. All rights reserved.

Originally published in Transactions of the Atomic Energy Society of Japan (ISSN 1347-2879), Vol. 11, No. 2, p.111-117

(2012) in Japanese. (Japanese version accepted: January 6, 2012)
} 
stay for long periods of time, such as schools and parks, can be decontaminated using basic tools that can be easily purchased at DIY stores. This trial was intended to test and evaluate a reduction in the air dose rate through the decontamination of a playground and playground equipment within an area of approximately $150 \mathrm{~m}^{2}$ located in a residential area where the order to evacuate was not issued.

\section{Decontamination Test}

\section{Introduction}

This test was intended to demonstrate the effects of ground surface decontamination on the air dose rate by decontaminating a playground with contaminated soil. A relatively small playground (approximately $150 \mathrm{~m}^{2}$ ) was chosen in order to confirm the localized contamination effect in an environment that is susceptible to background conditions in the surrounding area.

\section{Decontamination Test}

\section{(1) Decontamination plan}

Prior to decontamination, decontamination goals and plans needed to be established. Figure 1 provides a full view of the playground targeted for decontamination. The triangle-shaped playground is surrounded by apartments, houses, parking lots, and rice fields.

In order to establish the decontamination goal, the air dose rate was measured at three heights above the surface of the asphalt outside the playground $(1 \mathrm{~cm}, 50 \mathrm{~cm}$, and $100 \mathrm{~cm})$, without using a lead collimator (hereinafter referred to as "collimator"). The average values calculated from four measurement points were: $1.5 \mu \mathrm{Sv} / \mathrm{h}$ on the asphalt surface; $1 \mu \mathrm{Sv} / \mathrm{h}$ at a height of $50 \mathrm{~cm}$; and $0.9 \mu \mathrm{Sv} / \mathrm{h}$ at a height of $100 \mathrm{~cm}$. Since cesium on asphalt is dissolved in rainwater and can easily run off, the dose rate was lower than that of soil. Furthermore, because this relatively small playground is affected significantly by gamma rays from the surrounding area, an air dose rate of $0.9 \mu \mathrm{Sv} / \mathrm{h}$ (recorded $100 \mathrm{~cm}$ above the ground) was set as the decontamination goal.

Next, the contamination of all of the playground equipment was checked. The playground

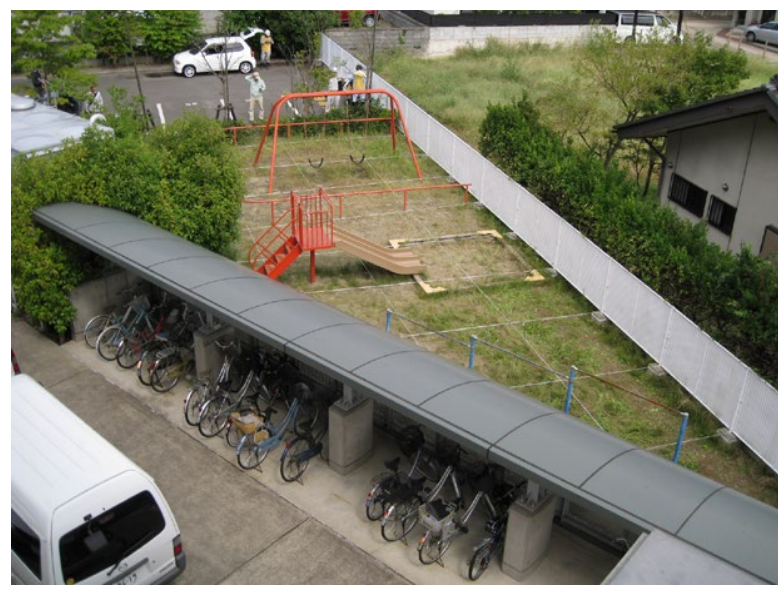

Figure 1 View of the playground before decontamination 
includes swings, a slide, a sandbox, equipment made of fiber reinforced plastic (FRP), and a horizontal bar, and plants are located at the stone-flagged entrance and around the gutters. Both concrete and iron grating covers are placed over the gutters, and the soil has been left unweeded.

At the time the test was carried out, Fukushima City made a recommendation to remove the top $5 \mathrm{~cm}$ of soil ${ }^{1)}$ and dig $1.5-\mathrm{m}$ deep burial holes (to be covered with $0.5 \mathrm{~m}$ of soil) ${ }^{1)}$. The demonstration aimed to remove a certain thickness of surface soil based on the measured radiation dose, but also to minimize the amount of material that had to be removed. Therefore, it was determined during the planning phase that the top $5 \mathrm{~cm}$ of soil would be removed from the entire playground area (approximately $150 \mathrm{~m}^{2}$ ) and that a burial hole would be dug that could contain the removed soil. The depth of the burial hole was designed so that $10.5 \mathrm{~m}^{3}$ of soil could be overlaid with a soil cover $0.5 \mathrm{~m}$ thick, based on the following formula: $150 \mathrm{~m}^{2} \times 5 \mathrm{~cm} \times$ loose soil volume factor. Since it was impossible to dig the hole by hand, heavy machinery was used to excavate a portion of planted area, where plants were pulled out. Concerning decontamination work in residential areas, it is important to demonstrate a method that the general public can implement. Therefore, except for the measurement instruments, we used tools that can be purchased from DIY stores, such as a high-pressure water sprayer and bamboo winnow. In addition, two working areas were created so that the work could proceed efficiently without the risk of re-contamination. Figure 2 shows the layout of the playground.

The decontamination was conducted in the order of playground equipment, planted areas, soil, and gutters, and ground leveling was performed last using Soilex ${ }^{2)}$, which generates less fugitive sand as additional soil. Considering the drainage function of the playground, surface compaction was performed during ground levelling so that the ground sloped toward the

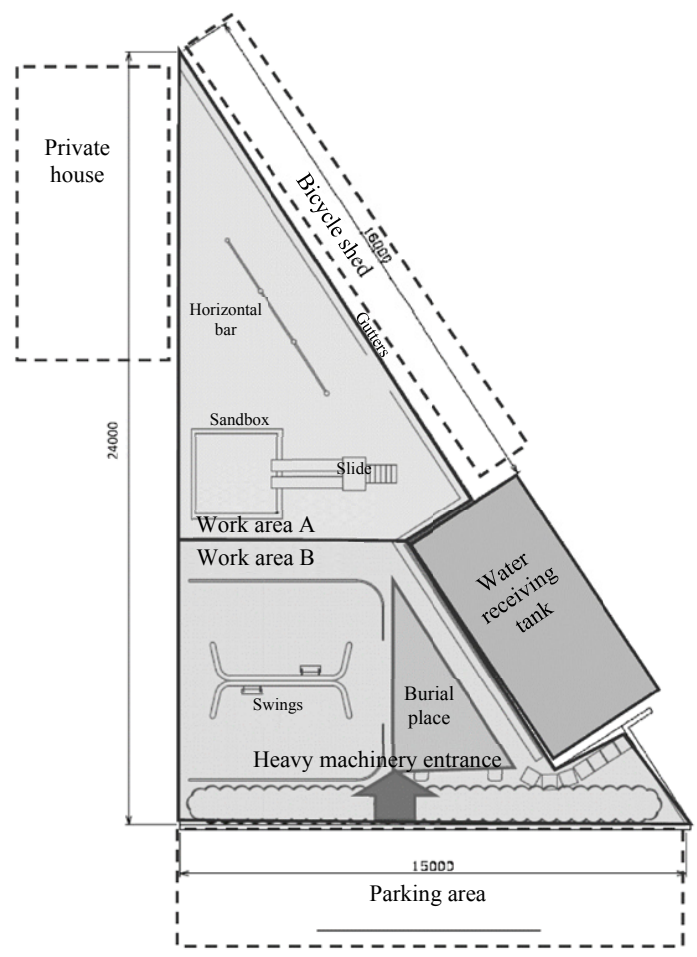

Figure 2 Layout of the playground lot 
gutters. Concerning the playground equipment, the elimination of loose contamination (which was not fixed firmly by paint, for example) was tested.

\section{(2) Radiation measurement method}

(a) Air dose rate

The air dose rate was measured for 30 seconds based on a time constant of $10 \mathrm{~s}$ using a NaI scintillation survey meter (Aloka, TCS-172) with a calibration constant of 1.0. The average of five measured values was recorded as the measurement value. The measurements were performed at the soil surface $(1 \mathrm{~cm})$, and at $50 \mathrm{~cm}$ and $100 \mathrm{~cm}$ above the ground.

When using the lead collimator for measurement on the surface, it was placed with the probe covered with a 7-mm-thick lead sheet (equivalent to a half-value layer of cesium (Cs) 137).

(b) Surface contamination

Surface contamination was measured at a distance of $1 \mathrm{~cm}$ from the measured object, using a GM counter tube (Aloka, TG133) with a counting efficiency of $43 \%$. When the background measurement was conducted, a 7-mm-thick lead sheet was placed between the measured object and the GM counter tube so that the detector would be hidden from the measured object.

When implementing the direct smear method, a filter paper used for the smears was placed inside a building with relatively low background radiation, enclosed with a lead wool mat $(760 \mathrm{~mm} \times 240 \mathrm{~mm}$, with a lead equivalent of $10 \mathrm{~mm})$, to create a background condition of around $100 \mathrm{cpm}$.

(c) Measurement before decontamination

We measured the air dose rate before decontamination. First, we divided the playground into a grid with each block measuring $2 \mathrm{~m} \times 2 \mathrm{~m}$. At the 43 intersection points, we measured the air dose rate at the three sample heights $(1 \mathrm{~cm}, 50 \mathrm{~cm}$, and $100 \mathrm{~cm}$ above the ground)

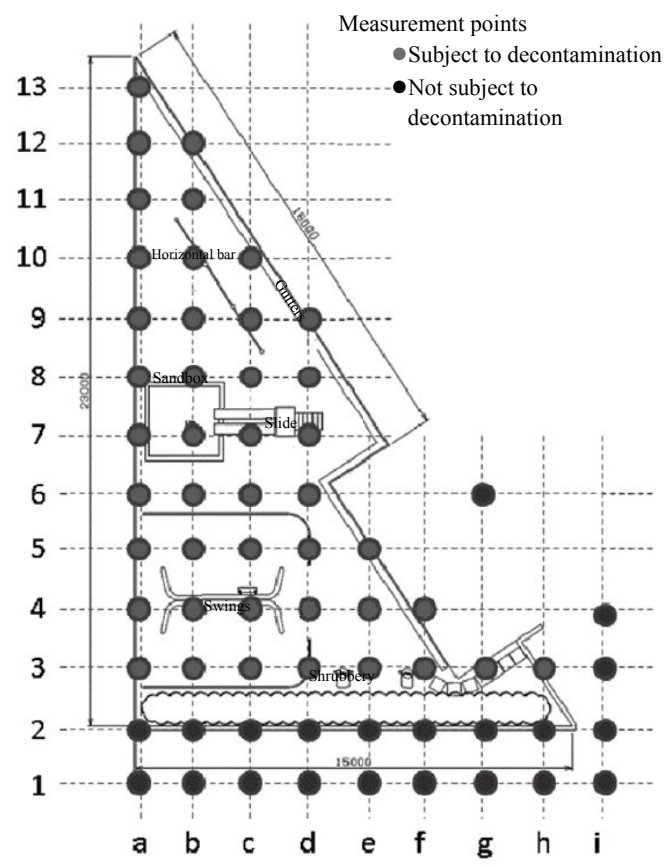

Figure 3 Air dose rate measurement points in the playground lot 
using the NaI scintillation survey meter. Figure 3 shows the positions of the measurement grid. Detailed measurement data are shown below in comparison with the values after decontamination; the average values were $2.4 \mu \mathrm{Sv} / \mathrm{h}$ at the soil surface, $1.8 \mu \mathrm{Sv} / \mathrm{h}$ at a height of $50 \mathrm{~cm}$, and $1.5 \mu \mathrm{Sv} / \mathrm{h}$ at a height of $100 \mathrm{~cm}$.

\section{(3) Decontamination method tested}

(a) Decontamination of horizontal bar

Before decontamination, measurements were conducted according to the smear method using smear filter papers. After this, the horizontal bar was washed using water, neutral detergent, orange oil-based detergent (orange oil acts as a surfactant), and a brush (car-washing brush with Pacquin and polypropylene bristles). Measurement was then repeated according to the smear method after decontamination. Rust was filed away with abrasive paper (\#80).

At the time of decontamination, the parts of the horizontal bar were washed in the order from higher to lower (while paying attention to the direction of water flow) and wiped with paper towels. However, we did not disassemble the fixing joints.

(b) Decontamination of the slide and swings

As described later, since washing with water and wiping produced a sufficient cleaning effect for the horizontal bar, the slide and swings were washed and brushed without detergent and eleven points were evaluated using the smear method. The same measurement method was used as described in Section II-2-(3)-(a) (Figure 4).

We decontaminated the fixing joints of the slide using a commercially available high-pressure water sprayer (water pressure $=7 \mathrm{MPa}$, straight nozzle) without disassembling.

(c) Decontamination of sandbox

As the area of the sandbox into which water flows from the slide was highly contaminated, and the frame of the sandbox was made of wood, decontamination of the sandbox was performed after dividing it into the following three areas: (a) an area with a high degree of

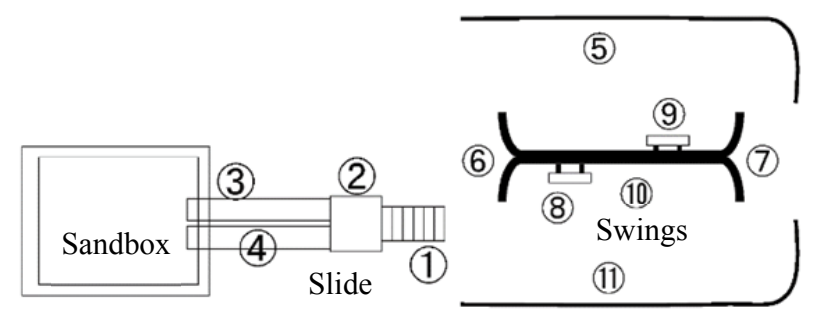

Figure 4 Air dose rate measurement points at and around the slide
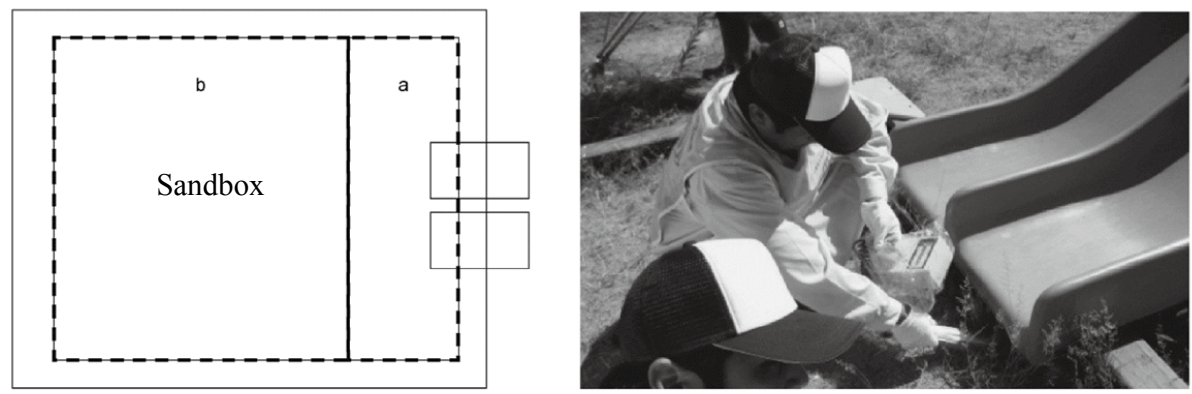

Figure 5 Air dose rate measurement points at the sandbox 
contamination, (b) an area with a low degree of contamination, and (c) the wooden frame (Figure 5). In each area, after eliminating garbage and weeds, and removing the top 1, 3, 5 , and $10 \mathrm{~cm}$ of the soil according to the topsoil removal method, we measured the air dose rate at the surface $(1 \mathrm{~cm})$ using a collimator and also measured the surface contamination density using a GM counter tube. For area (b), we performed the measurement at five points, positioned evenly, and evaluated the average value.

For the wooden frame, we implemented and evaluated four types of decontamination: water washing with a brush; wiping using a detergent containing orange oil; sanding with sandpaper; and sanding with an electric sander.

(d) Spot decontamination of soil

A circular area $100 \mathrm{~cm}$ in diameter was targeted for decontamination because it was less susceptible to the scattering effect of gamma radiation from the periphery of the site. After removing any garbage and weeds, the soil within the circle was then decontaminated according to the topsoil removal method. We removed the top $1 \mathrm{~cm}, 3 \mathrm{~cm}$, and $5 \mathrm{~cm}$ of soil and measured the air dose rate at heights of $1 \mathrm{~cm}, 50 \mathrm{~cm}$, and $100 \mathrm{~cm}$ above the surface using a GM counter tube.

(e) Decontamination of surface soil

As described later, since removing the soil up to $3 \mathrm{~cm}$ in depth was found to have a sufficient decontamination effect, decontamination was implemented by removing the top $3 \mathrm{~cm}$ of soil from the entire playground area. In this decontamination work, care was taken to remove the soil thinly and evenly using bamboo winnows and square shovels, which are used as farm tools. After decontamination, the air dose rate was measured at three heights $(1 \mathrm{~cm}, 50 \mathrm{~cm}$, and $100 \mathrm{~cm}$ ) at the same measurement points as shown in Figure 3. For measurements taken at the soil surface $(1 \mathrm{~cm})$, a collimator was also used as well as a GM counter tube.

(f) Decontamination of gutters

For the gutters (made of concrete and with a pit width of $18 \mathrm{~cm}$ and a pit depth of $17 \mathrm{~cm}$ ), garbage and sludge were first removed using tongs and shovels, respectively. The gutters were then washed with water and a brush (using scrubbing brushes with red fern bristles) before using a high-pressure washer (from a distance of $10 \mathrm{~cm}$ ). Since the gutters were approximately $30 \mathrm{~cm}$ deep, the air dose rate was measured at a height of $1 \mathrm{~cm}$ from the bottom.

(g) Decontamination of gutter covers

The gutters had both iron gratings and concrete covers $(25 \mathrm{~cm}$ wide $\times 60 \mathrm{~cm}$ long $\times$ $3.5 \mathrm{~cm}$ thick). Since the iron covers could be decontaminated by washing with water and brushes and the high-pressure washer, we conducted the test on the concrete covers. The decontamination effect was compared between water washing with brushes (scrubbing) and high-pressure washing.

(h) Shielding of buried soil

In order to check the shielding effect of the soil cover at the burial site, we measured the air dose rates $(1 \mathrm{~cm}, 50 \mathrm{~cm}$, and $100 \mathrm{~cm}$ above the surface $)$ with soil cover thicknesses of $10 \mathrm{~cm}, 20 \mathrm{~cm}, 30 \mathrm{~cm}$, and $35 \mathrm{~cm}$.

\section{(4) Test results}

(a) Decontamination of horizontal bar

Table 1 shows the results of decontamination of the horizontal bar. Each measured value (net) was calculated by deducting the background value from the raw (gross) measured value. As a result, we found that loose contamination (which was not fixed firmly by paint, for example) could be eliminated by water washing.

(b) Decontamination of slide and swings 
Table 1 Decontamination effects for the horizontal bar

\begin{tabular}{ccccc} 
& & & & (Unit: cpm) \\
\hline Measurement point & $\begin{array}{c}\text { Water } \\
\text { washing }\end{array}$ & $\begin{array}{c}\text { Mild } \\
\text { detergent }\end{array}$ & Sandpaper & $\begin{array}{c}\text { Detergent } \\
\text { containing } \\
\text { orange oil }\end{array}$ \\
\hline $\begin{array}{c}\text { Before } \\
\text { decontamination } \\
\text { value } \\
\text { (Gross) } \\
\text { Measured } \\
\text { value } \\
\text { (Net) }\end{array}$ & 100 & 80 & 130 & 270 \\
\hline $\begin{array}{c}\text { Measured } \\
\text { value } \\
\text { (Gross) } \\
\text { decontamination } \\
\text { Measured } \\
\text { value } \\
\text { (Net) }\end{array}$ & 100 & 100 & 100 & 100 \\
\hline Decline rate $(\%)$ & 0 & 0 & 0 & 0 \\
\hline
\end{tabular}

Table 2 Decontamination effects for the slide

\begin{tabular}{|c|c|c|c|c|c|}
\hline \multirow{2}{*}{\multicolumn{2}{|c|}{ Measurement point }} & & & \multicolumn{2}{|c|}{ (Unit:cpn } \\
\hline & & (1) & (2) & (3) & (4) \\
\hline \multirow{2}{*}{$\begin{array}{c}\text { Before } \\
\text { decontamination }\end{array}$} & $\begin{array}{l}\text { Measured } \\
\text { value } \\
\text { (Gross) }\end{array}$ & 180 & 200 & 190 & 200 \\
\hline & $\begin{array}{l}\text { Measured } \\
\text { value } \\
\text { (Net) }\end{array}$ & 80 & 100 & 90 & 70 \\
\hline \multirow{2}{*}{$\begin{array}{c}\text { After } \\
\text { decontamination }\end{array}$} & $\begin{array}{l}\text { Measured } \\
\text { value } \\
\text { (Gross) }\end{array}$ & 100 & 100 & 100 & 100 \\
\hline & $\begin{array}{l}\text { Measured } \\
\text { value } \\
\text { (Net) }\end{array}$ & 0 & 0 & 0 & 0 \\
\hline \multicolumn{2}{|c|}{ Decline rate $(\%)$} & 100 & 100 & 100 & 100 \\
\hline
\end{tabular}

Table 3 Decontamination effects for swings

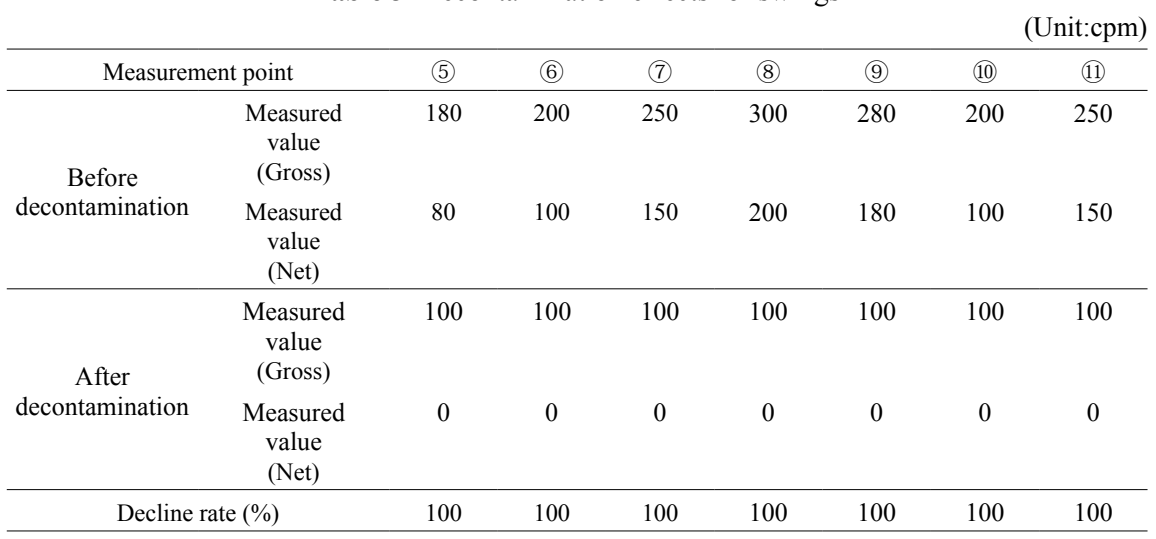

Table 2 and Table 3 show the results of decontamination of the slide and swings, respectively. Based on these data, it was found that loose contamination could be eliminated by water washing.

(c) Decontamination of sandbox

Table 4 shows the result of decontamination of the sandbox. By removing the top $5 \mathrm{~cm}$ of soil, areas a and b were decontaminated to $350 \mathrm{cpm}$ and $110 \mathrm{cpm}$, respectively. After 
removing the top $10 \mathrm{~cm}$ of soil, both areas were decontaminated to $30 \mathrm{cpm} ; 70-90 \%$ of the contamination was contained in the top $1 \mathrm{~cm}$ of soil. Table 5 shows the results of decontamination of the wooden frame. Sanding but not washing was required to achieve a sufficient decontamination effect.

(d) Effect of spot decontamination of soil

Table 6 shows the results of the measurements conducted at the center of a circle with a diameter of $1 \mathrm{~m}$. Although this showed $100 \%$ decontamination at the surface $(1 \mathrm{~cm}$ above the ground), the air dose rate at a height of $100 \mathrm{~cm}$ above the ground was reduced by only $11 \%$. This is because the greater the height, the more gamma rays from the periphery of the site reached the detector. This means that performing spot decontamination alone contributes little to the reduction of air dose rate in areas of widespread contamination.

(e) Effect of surface decontamination of soil

Table 7 shows the average, maximum, and minimum values for all measurement points. Not only was the soil surface decontaminated as in the case of spot decontamination, but the air dose rate also declined more than it did following spot decontamination.

(f) Decontamination of gutters

Table 8 shows the results of decontamination of the gutters. Although the elimination of

Table 4 Decontamination effects for the sandbox

\begin{tabular}{|c|c|c|c|c|c|c|c|c|}
\hline \multirow[b]{3}{*}{$\begin{array}{c}\text { Decontamination } \\
\text { item }\end{array}$} & \multicolumn{4}{|c|}{ Area a } & \multicolumn{4}{|c|}{ Area $b$ (average of 5 points) } \\
\hline & \multicolumn{2}{|c|}{ Air dose rate } & \multicolumn{2}{|c|}{ Surface contamination } & \multicolumn{2}{|c|}{ Air dose rate } & \multicolumn{2}{|c|}{ Surface contamination } \\
\hline & $\begin{array}{c}\text { Measured } \\
\text { value } \\
(\mu \mathrm{Sv} / \mathrm{h})\end{array}$ & $\begin{array}{l}\text { Decline } \\
\text { rate } \\
(\%)\end{array}$ & $\begin{array}{l}\text { Measured } \\
\text { value } \\
\text { Net }(\mathrm{cpm})\end{array}$ & $\begin{array}{l}\text { Decline } \\
\text { rate } \\
(\%)\end{array}$ & $\begin{array}{c}\text { Measured } \\
\text { value } \\
(\mu \mathrm{Sv} / \mathrm{h})\end{array}$ & $\begin{array}{l}\text { Decline } \\
\text { rate } \\
(\%)\end{array}$ & $\begin{array}{c}\text { Measured } \\
\text { value } \\
\text { Net }(\mathrm{cpm})\end{array}$ & $\begin{array}{c}\text { Decline rate } \\
(\%)\end{array}$ \\
\hline $\begin{array}{c}\text { Before } \\
\text { decontamination }\end{array}$ & 14 & - & 9,500 & - & $2.4 \pm 0.4$ & - & $842 \pm 207$ & - \\
\hline $\begin{array}{c}\text { Elimination of } \\
\text { garbage and weeds }\end{array}$ & 13 & 7 & - & - & $2.3 \pm 0.3$ & 5 & - & - \\
\hline $\begin{array}{l}\text { Removal of the top } \\
1 \mathrm{~cm} \text { of soil }\end{array}$ & 3.6 & 74 & 7,700 & 18.9 & $2.1 \pm 0.3$ & 11 & $900 \pm 89$ & -6.9 \\
\hline $\begin{array}{l}\text { Removal of the top } \\
3 \mathrm{~cm} \text { of soil }\end{array}$ & 2.1 & 85 & 1,000 & 89.5 & $1.3 \pm 0.3$ & 45 & $1,000 \pm 0$ & -18.8 \\
\hline $\begin{array}{l}\text { Removal of the top } \\
5 \mathrm{~cm} \text { of soil }\end{array}$ & 0.8 & 94 & 350 & 96.3 & $0.6 \pm 0.0$ & 74 & $110 \pm 34$ & 86.9 \\
\hline $\begin{array}{l}\text { Removal of the top } \\
10 \mathrm{~cm} \text { of soil }\end{array}$ & 0.5 & 96 & 30 & 99.7 & $0.4 \pm 0.1$ & 83 & $30 \pm 85$ & 96.4 \\
\hline
\end{tabular}

Table 5 Decontamination effects for sandbox wood frame

\begin{tabular}{|c|c|c|c|c|c|}
\hline & & & & & Unit:cpn \\
\hline \multicolumn{2}{|l|}{ Measurement point } & $\begin{array}{c}\text { Water } \\
\text { washing }\end{array}$ & $\begin{array}{l}\text { Detergent } \\
\text { containing } \\
\text { orange oil }\end{array}$ & $\begin{array}{l}\text { Sanding } \\
\text { with } \\
\text { sandpaper }\end{array}$ & $\begin{array}{l}\text { Sanding } \\
\text { with } \\
\text { electric } \\
\text { sander } \\
\end{array}$ \\
\hline \multirow{2}{*}{$\begin{array}{c}\text { Before } \\
\text { decontamination }\end{array}$} & $\begin{array}{l}\text { Measured } \\
\text { value } \\
\text { (Gross) }\end{array}$ & 4,500 & 4,500 & 4,500 & 4,500 \\
\hline & $\begin{array}{l}\text { Measured } \\
\text { value } \\
\text { (Net) }\end{array}$ & 4,200 & 4,200 & 4,200 & 4,200 \\
\hline \multirow{2}{*}{$\begin{array}{c}\text { After } \\
\text { decontamination }\end{array}$} & $\begin{array}{l}\text { Measured } \\
\text { value } \\
\text { (Gross) }\end{array}$ & 3,000 & 2,100 & 1,250 & 330 \\
\hline & $\begin{array}{l}\text { Measured } \\
\text { value } \\
\text { (Net) }\end{array}$ & 2,700 & 1,800 & 950 & 30 \\
\hline \multicolumn{2}{|c|}{ Decline rate $(\%)$} & 36 & 57 & 77 & 99 \\
\hline
\end{tabular}


sludge, water washing with brushes, and high-pressure washing had a high decontamination effect, the high-pressure washing showed the greatest effect.

(g) Decontamination of gutter cover

It was found that high-pressure washing produced a greater decontamination effect than water washing with brushes (Table 9).

(h) Results of shielding the buried soil

In order to check the shielding effect of soil cover at the burial site, air dose rates were

Table 6 Spot decontamination effects on soil

\begin{tabular}{|c|c|c|c|c|c|c|c|c|}
\hline \multirow[b]{3}{*}{ Decontamination item } & \multicolumn{4}{|c|}{ Surface $(1 \mathrm{~cm})$} & \multirow{2}{*}{\multicolumn{2}{|c|}{$\begin{array}{c}50 \mathrm{~cm} \\
\text { Air dose rate }\end{array}$}} & \multirow{2}{*}{\multicolumn{2}{|c|}{$\begin{array}{l}100 \mathrm{~cm} \\
\text { Surface contamination }\end{array}$}} \\
\hline & Air do & e rate & Surface col & amination & & & & \\
\hline & $\begin{array}{c}\text { Measured } \\
\text { value } \\
(\mu \mathrm{Sv} / \mathrm{h})\end{array}$ & $\begin{array}{c}\text { Decline } \\
\text { rate } \\
(\%)\end{array}$ & $\begin{array}{l}\text { Measured } \\
\text { value } \\
\text { Net }(\mathrm{cpm})\end{array}$ & $\begin{array}{c}\text { Decline } \\
\text { rate } \\
(\%)\end{array}$ & $\begin{array}{l}\text { Measured } \\
\text { value } \\
(\mu \mathrm{Sv} / \mathrm{h})\end{array}$ & $\begin{array}{c}\text { Decline } \\
\text { rate } \\
(\%)\end{array}$ & $\begin{array}{c}\text { Measured } \\
\text { value } \\
(\mu \mathrm{Sv} / \mathrm{h})\end{array}$ & $\begin{array}{c}\text { Decline } \\
\text { rate } \\
(\%)\end{array}$ \\
\hline Before decontamination & 2.6 & - & 1,400 & - & 2.1 & - & 1.8 & - \\
\hline $\begin{array}{c}\text { Elimination of garbage } \\
\text { and weeds }\end{array}$ & 2.5 & 4 & 1,400 & 0 & 2.1 & 0 & 1.7 & 6 \\
\hline $\begin{array}{c}\text { Removal of the top } 1 \mathrm{~cm} \\
\text { of soil }\end{array}$ & 1.3 & 50 & 400 & 71 & 1.9 & 10 & 1.7 & 6 \\
\hline $\begin{array}{c}\text { Removal of the top } 3 \mathrm{~cm} \\
\text { of soil }\end{array}$ & 0.9 & 65 & 150 & 89 & 1.7 & 19 & 1.6 & 11 \\
\hline $\begin{array}{l}\text { Removal of the top } 5 \mathrm{~cm} \\
\text { of soil }\end{array}$ & 0.8 & 69 & 0 & 100 & 1.7 & 19 & 1.6 & 11 \\
\hline
\end{tabular}

Table 7 Decontamination effects for ground surface soil

\begin{tabular}{|c|c|c|c|c|c|c|}
\hline \multirow{2}{*}{$\begin{array}{l}\text { Measurement } \\
\text { point }\end{array}$} & \multicolumn{3}{|c|}{ Before decontamination $(\mu \mathrm{Sv} / \mathrm{h})$} & \multicolumn{3}{|c|}{ After decontamination $(\mu \mathrm{Sv} / \mathrm{h})$} \\
\hline & Average $^{\text {a) }}$ & Max. & Min. & Average $^{\text {a) }}$ & Max. & Min. \\
\hline $100 \mathrm{~cm}$ & 1.5 & 1.9 & 1.0 & 0.6 & 1.1 & 0.4 \\
\hline $50 \mathrm{~cm}$ & 1.8 & 2.4 & 1.2 & 0.6 & 1.0 & 0.3 \\
\hline $1 \mathrm{~cm}$ & 2.4 & 5 & 1.6 & 0.4 & 1.1 & 0.3 \\
\hline (Collimate) & - & - & - & 0.2 & 0.4 & 0.1 \\
\hline $\begin{array}{c}\text { Surface } \\
\text { contamination } \\
(\mathrm{Net})(\mathrm{cpm})\end{array}$ & - & 一 & - & 18 & 550 & 0 \\
\hline
\end{tabular}

a) Measurements were taken at 43 intersection points generated by dividing the playground lot into a $2 \mathrm{~m} \times 2 \mathrm{~m}$ grid.

Table 8 Decontamination effects for gutters

\begin{tabular}{cccc}
\hline $\begin{array}{c}\text { Decontamination } \\
\text { method }\end{array}$ & $\begin{array}{c}\text { Before } \\
\text { decontamination } \\
(\mu \mathrm{Sv} / \mathrm{h})\end{array}$ & $\begin{array}{c}\text { After } \\
\text { decontamination } \\
(\mu \mathrm{Sv} / \mathrm{h})\end{array}$ & $\begin{array}{c}\text { Decline rate } \\
(\%)\end{array}$ \\
\hline Elimination of garbage & 2.28 & 3.32 & -46 \\
Elimination of sludge & 2.11 & 0.68 & 68 \\
Water washing with brushes & 1.4 & 0.43 & 69 \\
High-pressure washing & 2.75 & 0.74 & 73 \\
\hline
\end{tabular}

Table 9 Decontamination effects for gutter covers

\begin{tabular}{cccc}
\hline Decontamination method & $\begin{array}{c}\text { Before } \\
\text { decontamination } \\
(\mathrm{cpm})\end{array}$ & $\begin{array}{c}\text { After } \\
\text { decontamination } \\
(\mathrm{cpm})\end{array}$ & $\begin{array}{c}\text { Decline rate } \\
(\%)\end{array}$ \\
\hline $\begin{array}{c}\text { Water washing } \\
\text { with brushes } \\
\text { High-pressure } \\
\text { washing }\end{array}$ & 6,000 & 2,500 & 58 \\
\hline
\end{tabular}


Table 10 Shielding effect for removed topsoil

\begin{tabular}{cccccc}
\hline $\begin{array}{c}\text { Measurement } \\
\text { height }\end{array}$ & $0 \mathrm{~cm}$ & $10 \mathrm{~cm}$ & $20 \mathrm{~cm}$ & $30 \mathrm{~cm}$ & $35 \mathrm{~cm}$ \\
\hline $100 \mathrm{~cm}$ & 1.2 & 0.6 & 0.5 & 0.5 & 0.5 \\
$50 \mathrm{~cm}$ & 1.4 & 0.6 & 0.5 & 0.5 & 0.4 \\
$1 \mathrm{~cm}$ & 2.3 & 0.6 & 0.5 & 0.4 & 0.4 \\
$1 \mathrm{~cm}$ & - & - & - & - & 0.1 \\
\hline
\end{tabular}

measured at $50 \mathrm{~cm}$ and $100 \mathrm{~cm}$ above the ground at soil thicknesses of $10 \mathrm{~cm}, 20 \mathrm{~cm}, 30 \mathrm{~cm}$ and $35 \mathrm{~cm}$. The measurements were evaluated based on the average values measured at five points. Table 10 shows the measurement results.

\section{Evaluation of Decontamination}

In the case of loose contamination of the playground equipment, water washing produced a sufficient decontamination effect. However, the joint fixings of the playground equipment also need to be washed thoroughly and this involves disassembly and reassembly. Contamination adhering to the equipment also needs to be eliminated by removing the paint and replacing parts.

In the case of the sandbox, it was sufficiently decontaminated by removing the top $10 \mathrm{~cm}$ of sand. However, given that children dig and play in the sand, the landowner requested that the sand be replaced to a depth of $20 \mathrm{~cm}$.

Concerning the wooden frame of the sandbox, the decontamination using an electric sander resulted in the highest removal of radioactive materials. However, it is important to use dust collectors to prevent scattering of contaminated wood dust. Wearing a mask is also required to prevent inhalation of the contaminated wood dust.

Spot decontamination of the soil was found to be effective in removing contaminated soil, but to have very little effect in terms of decreasing the air dose rate. In addition, removing the top $3 \mathrm{~cm}$ of soil removed approximately $90 \%$ of the contamination. This accords with the fact that $95 \%$ of radioactive cesium was distributed in the soil up to a depth of $2.5 \mathrm{~cm}^{3)}$. In addition, there was a $2-3 \mathrm{~cm}$ layer generated by weed mulch on the top of the playground's soil. Therefore, removing this layer produced a sufficient decontamination effect.

The surface decontamination of the soil reduced the air dose rate to below $0.9 \mu \mathrm{Sv} / \mathrm{h}$, which had been set as the target value. Since a lower air dose rate was achieved when using a collimator, it would appear that the air dose rate was increased by radiation from the periphery of the site rather than from the playground itself. When a collimator was used, the average dose rate at a height of $1 \mathrm{~cm}$ was $0.2 \mu \mathrm{Sv} / \mathrm{h}$. On the other hand, the average air dose rate at a height of $100 \mathrm{~cm}$ was $0.6 \mu \mathrm{Sv} / \mathrm{h}$. This difference of $0.4 \mu \mathrm{Sv} / \mathrm{h}$ is considered to result from the influence of nearby buildings. On the other hand, the average air dose rate at a height of $100 \mathrm{~cm}$ was $1.5 \mu \mathrm{Sv} / \mathrm{h}$ before decontamination but declined by $0.9 \mu \mathrm{Sv} / \mathrm{h}$ after the topsoil was removed. From this, it was found that contamination from the soil surface contributed to more than half of the dose rate measured in the air at a height of $100 \mathrm{~cm}$. It was also found that air dose rates were effectively reduced by decontaminating the soil directly beneath the surface. The dose rate at which decontamination is required at present is $0.23 \mu \mathrm{Sv} / \mathrm{h}^{4)}$, which was calculated based on the annual additional radiation dose of $1 \mathrm{mSv}$. Since the average surface dose rate of soil is $0.2 \mu \mathrm{Sv} / \mathrm{h}$, the air dose rate is expected to be closer to $0.2 \mu \mathrm{Sv} / \mathrm{h}$ as the decontaminated area 
increases.

On the other hand, the dose rate of the gutters increased in spite of removing the garbage. This is considered to be the result of contaminated sludge being moved to the measurement site, although the measurements were taken in the same place before and after the garbage was removed. In addition, washing with brushes achieved the same level of decontamination as high-pressure washing.

The concrete covers were highly contaminated. Although high-pressure washing had a high decontamination effect, the contamination level could not be reduced to below $1,000 \mathrm{cpm}$. This means that radioactive cesium gained entry into the concrete joints. Therefore, a method that enables these joints to be washed is required in order to decontaminate the concrete completely. In this test, we used a 7-MPa high-pressure water sprayer equipped with a straight nozzle, and confirmed that high-pressure washing was effective to a certain degree. Although the effect of a device equipped with a rotary nozzle (which can produce higher pressure) needs to be tested for surface decontamination, such devices may be higher in cost than those easily purchased at DIY stores. Therefore, this is an issue for further study.

Concerning the shielding effect of the buried soil, it was found that a thickness of $30 \mathrm{~cm}$ could shield approximately $80 \%$ of the radiation dose rate. Since approximately $3 \mathrm{~cm}$ of topsoil was removed, there was no need to dig a $10-\mathrm{m}^{3}$ hole as originally planned; covering the soil to a thickness of approximately $0.3 \mathrm{~m}$ was sufficient to produce a superior shielding effect.

Finally, the following points were learned as a result of the decontamination tests, although more data need to be collected in the future:

First, a method for decontaminating the wooden frame as well as the rubber steps of the slide was also tested. For this, a mold-removing agent containing hypochlorous acid was used in order to remove cesium together with the dirt on the surface. This method produced decontamination effects but resulted in the bleaching of the wooden frame. In the case of the rubber steps, the dirt was removed by the foam that was generated when the detergent was sprayed on. There is a best moment to wipe off the detergent foam before the dirt adhered again, although it was not possible to conduct a test to verify this.

Second, combining an electrical sander with a dust collector expanded the scope of the decontamination. A field test of effective and efficient decontamination using general-purpose cleaning devices is expected before full-scale decontamination commences.

Figure 6 shows a view of the playground after decontamination. This shows how the

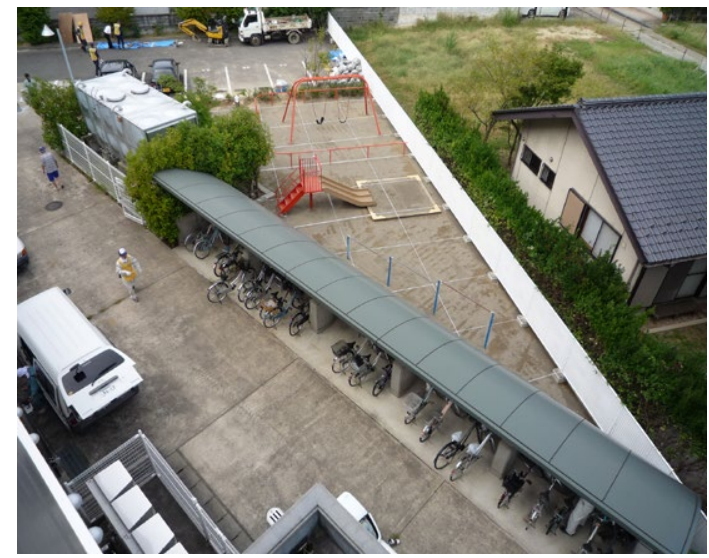

Figure 6 View of the playground after decontamination 
playground was cleaned in comparison to its condition before decontamination as shown in Figure 1

\section{Conclusions}

The loose contamination on the playground equipment was sufficiently eliminated by washing with water. Soil can be decontaminated by removing approximately $3 \mathrm{~cm}$ of topsoil. Although the gutters were decontaminated using water washing with brushes and high-pressure washing, there is an issue concerning the elimination of radioactive materials that have gained entry into concrete joints. On the whole, this demonstration has shown that implementing surface decontamination can reduce air dose rates at a height of $100 \mathrm{~cm}$, and surface decontamination was shown to be more effective at reducing air dose rates than spot decontamination.

\section{Afterword}

In this test, various decontamination methods were trialed for the purpose of checking the effect of surface decontamination on air dose rates for a playground with an area of $150 \mathrm{~m}^{2}$. Loose contamination on the playground equipment was shown to be removable by washing with water and brushes. For soil, implementing surface decontamination by removing approximately $3 \mathrm{~cm}$ of topsoil lowered the air dose rate at a height of $100 \mathrm{~cm}$ to $0.3 \mu \mathrm{Sv} / \mathrm{h}$ below the original target of $0.9 \mu \mathrm{Sv} / \mathrm{h}$. For the gutters and the concrete gutter covers, high-pressure washing at a pressure of $7 \mathrm{MPa}$ proved to be effective to a certain degree, but eliminating contamination in the concrete joints proved to be problematic. When placing a cover of soil on material removed during decontamination, a thickness of $30 \mathrm{~cm}$ was found to be effective in shielding approximately $80 \%$ of the radiation.

The data collected demonstrate that implementing surface decontamination can be more effective at reducing air dose rates than implementing spot decontamination in hot spots.

The results of this test, conducted in accordance with the decontamination instructions issued by the Fukushima Prefecture ${ }^{5}$, are summarized in a 17-minute video. The video is posted on the Japan Atomic Energy Agency website ${ }^{6}$ and is also utilized in decontamination seminars held by the Fukushima Prefecture.

We are very grateful to Fukushima Prefecture and Fukushima City for their supporting in helping us to implement this test and evaluation.

\section{References}

1) Fukushima City website: http://www.city.fukushima.fukushima.jp/. [in Japanese]

2) Highclay Corporation website: http: // www.highclay.co.jp /products/index.html. [in Japanese]

3) Agriculture, Forestry and Fisheries Research Council, Radioactive material removal technologies (decontamination technology) of agricultural soil are explained in [Appendix 4], http://www.s.affrc.go.jp/ docs/press/pdf/110914-10.pdf, 2011.9.14. [in Japanese]

4) The Ministry of the Environment, 1st Safety Assessment Committee / Environment Recovery Assessment Committee Appendix 2 Concept of Additional Exposure Dose of $1 \mathrm{mSv} /$ year, http://www.env. go.jp/jishin/rmp/conf/g01-mat4.pdf, 2011.10.10. [in Japanese]

5) Disaster Control Headquarters of Fukushima Prefecture, "Guidance on measures to reduce radiation dose in living areas," http://www.pref.fukushima.jp/j/tebiki0715.pdf, 2011.7.15. [in Japanese]

6) Japan Atomic Energy Agency, “About Decontamination Work,” http://www.jaea.go.jp/fukushima/josenvtr.html. [in Japanese] 